\title{
Assessing S. mansoni prevalence in Biomphalaria snails in the Gombe ecosystem of western Tanzania: the importance of DNA sequence data for clarifying species identification
}

\author{
Jared S. Bakuza ${ }^{1,2^{*}}$, Robert Gillespie ${ }^{1}$, Gamba Nkwengulila ${ }^{3}$, Aileen Adam ${ }^{1}$, Elizabeth Kilbride ${ }^{1}$ and Barbara K. Mable ${ }^{1}$
}

\begin{abstract}
Background: Snails are essential for the transmission and maintenance of schistosomiasis in endemic areas, as they serve as intermediate hosts for schistosome parasites. A clear understanding of the snail species present, their local distribution and infection status is therefore a prerequisite for effective control of schistosomiasis. The purpose of this study was to establish the infection status and distribution of Schistosoma mansoni in snails in the Gombe area along the shores of Lake Tanganyika in western Tanzania, using both detection of cercarial shedding and molecular approaches.
\end{abstract}

Methods: Snails were collected from streams located close to human settlements in Gombe National Park, as well as from nearby villages (Kiziba, Mtanga, Mwamgongo and Bugamba) and the largest town in the region (Kigoma). Snails were individually exposed to light to induce shedding of schistosome larvae, which were examined using a compound light microscope. Additionally, the internal transcribed spacer (ITS) region of the ribosomal RNA gene cluster was simultaneously amplified in both snails and their trematodes using a single polymerase chain reaction $(P C R)$ and sequenced to confirm species identification.

Results: Snails morphologically identified as Biomphalaria pfeifferi were present in all streams except at Mtanga but their distribution was patchy in both time and space. Sequencing of PCR products indicated that not all snails were $B$. pfeifferi. None of the snails from Gombe or Bugamba shed schistosome larvae, while larvae were shed at all other sites. Overall, an infection prevalence of only $12 \%$ was observed in snails based on cercarial shedding. While $47 \%$ of the snails were PCR-positive for the $500 \mathrm{bp}$ ITS fragment, which was predicted to indicate infection with S. mansoni, sequence data demonstrated that these bands are not species-specific and can be amplified from other trematode infections. In addition, a 1000 bp band was amplified in 14\% of samples, which was identified as a trematode in the family Derogenidae.

Conclusions: The results support the previous assumption that B. pfeifferi snails may be involved in transmitting schistosomiasis in the area but suggest that the community structure of both snails and trematodes may be more complicated than previously thought. This emphasises the importance of confirming species identifications using sequencing, rather than relying only on PCR-based diagnostics or cercarial shedding.

Keywords: PCR diagnostics, Cercarial shedding, Prevalence, Schistosoma mansoni, Biomphalaria pfeifferi

\footnotetext{
* Correspondence: bakuzajared@yahoo.co.uk

'Institute of Biodiversity, Animal Health and Comparative Medicine, College

of Medical, Veterinary and Life Sciences, University of Glasgow, Glasgow, UK

${ }^{2}$ Department of Biological Sciences, Dar es Salaam University College of

Education, Dar es Salaam, Tanzania

Full list of author information is available at the end of the article
} 


\section{Background}

Studies on the transmission of intestinal schistosomiasis caused by $S$. mansoni (family Schistosomatidae) in humans have shown that the disease is acquired in areas where people come in contact with a water body containing infected snails [1]. The role of snail intermediate hosts in the transmission and maintenance of schistosomiasis is thus very important. Hence, knowledge of snail distribution and habitat preference is a crucial tool for understanding the epidemiology and control of the disease [2].

Different species of Schistosoma have a particular set of snail species that act as competent intermediate hosts [3] but this is complicated by the fact that most of the snail hosts belong to species complexes that have not always been fully disentangled [3, 4]. In Tanzania, for example, urogenital schistosomiasis (caused by S. haemotobium) is transmitted by four snail species belonging to the genus Bulinus. Of these, Bu. nasutus and Bu. globosus are widely distributed in the country both on mainland Tanzania and on the islands of Zanzibar (Unguja and Pemba), whereas $\mathrm{Bu}$. africanus and $\mathrm{Bu}$. truncatus are only found on the mainland [5]. Intestinal schistosomiasis (caused by $S$. mansoni) is transmitted by planorbid snails of the genus Biomphalaria. Of these, B. pfeifferi is thought to occur in most parts of the country except on the coastal belt and the islands of Zanzibar [6,7], whereas B. sudanica is found in the northern part of the country and B. choanomphala is confined to the shores of Lake Victoria $[5,6]$. However, clear identities and distribution of snail species and their role as vectors of schistosomiasis are poorly known, particularly in the western part of Tanzania [7]. For example, Lake Tanganyika has been regarded as possibly being schistosomiasis-free because most of its shores are rocky and constantly pounded by heavy waves, which might be detrimental to snail survival [8]. However, the lake is fed by multiple mountain streams, which could provide suitable snail habitats. Snails identified as Biomphalaria have been found in Gombe National Park close to the shores of Lake Tanganyika and $S$. mansoni infections have been diagnosed in nonhuman primates in the areas [9]. However, which snail species were present and capable of transmitting the parasites within the park and in the surrounding human-inhabited areas was not established.

Furthermore, a recent study [10] found unexpectedly high prevalence of $S$. mansoni in humans in Gombe and adjacent areas, with Kato-Katz detection of eggs from faeces in up to $45 \%$ of adults and $90 \%$ of children sampled in the villages adjacent to the park. However, there was extensive variation among villages in the number of positive individuals. It is possible that physical barriers to snail dispersal in the area caused by mountains and valleys may have caused low or no migration of snails between villages, which could result in variation between sites in the presence or absence of snails and their schistosome infection status. The highest prevalence of $S$. mansoni was in the village (Mwamgongo) closest to the Gombe National Park, which could increase the risk of cross-transmission between humans and non-human primates if animals and humans share water sources containing competent snail hosts. This hypothesis is difficult to assess without detailed knowledge about the distribution of snail species in the area and their infection status with schistosomes.

Diagnosis of schistosomes in their snail intermediate hosts has traditionally relied on exploiting the propensity of snails to shed cercaria when exposed to light, using microscopy identification of schistosome cercariae [11]. However, a limitation of this approach is that it can only identify patent infections [12]. It is also difficult to distinguish between other closely related trematodes infecting vertebrate hosts, such as the rodent-associated $S$. rodhaini, which is also in the $S$. mansoni group and can hybridise with S. mansoni [13, 14]. Other approaches have thus been developed for diagnosing infections in humans and snails [1], with some exploiting antibodies produced by infected individuals [15] or molecular techniques targeting repeat regions of DNA [12, 16, 17]. Molecular-based identification using the polymerase chain reaction (PCR) can be more sensitive at detecting low levels of infection, but the relatively higher cost and inefficient use in the field means that microscopy has instead been promoted and is still preferable under some situations [18]. However, an advantage of PCR over microscopy-based techniques is the ability to diagnose multiple infections with different parasites [19], particularly when combined with sequencing to confirm species identification [20]. A particularly common approach is to base such diagnostics on amplification of the internal transcribed spacer regions (ITS) of the ribosomal DNA array because of extensive length polymorphism that can be used to distinguish certain parasite species [21, 22]. This can be combined with restriction enzyme digestion to enable detection of variants even within species in some cases [22], which can provide a rapid and cheaper means of screening large number of individuals than sequencing. However, unless at least some representative variants are sequenced, there is a risk that new species, genetic variants within species, or closely related species (such as S. rodhaini) will be mis-assigned based only on fragment size. In principle an additional advantage of using the ITS region is that there is potential to simultaneously amplify the host or vector and the parasites using a single PCR because universal conserved primers can be designed in the flanking genes (18S and 5.8S) [23]. However, this strategy has not previously been applied to trematodes. Such an approach would be beneficial because amplification of the host or vector DNA 
can act as an internal control of DNA quality to interpret presence or absence of parasites and it is cheaper and easier for field-based surveys than using specific primers to target each species separately.

The purpose of this study was to identify the species of snail vectors and parasites present in the Gombe National Park ecosystem along Lake Tanganyika. PCRbased screening using general ITS1 primers that amplify DNA from both snail hosts and trematodes was initially compared with microscopy-based cercarial shedding, to test their relative sensitivity and specificity. Bands predicted to correspond to particular species of snails and parasites were then sequenced, to determine whether there was more variation present than would have been predicted based only on diagnostic PCR. The ultimate aim was to make recommendations for surveillance programmes to monitor transmission dynamics of schistosome prevalence in snails, humans and nonhuman primates in the Gombe area. Results are thus discussed in relation to $S$. mansoni infection status of humans and baboons sampled from the same geographical region [10].

\section{Methods}

\section{Snail collection and identification}

The study was conducted in the Gombe ecosystem along the shores of Lake Tanganyika in western Tanzania (Fig. 1). Sampled streams were strategically chosen to be in close proximity to human activities. Snails were sampled from streams at Gombe National Park (Kakombe and Mkenke) and four of the surrounding villages: Kiziba (Bumba and unnamed stream), Mtanga (Mtanga), Mwamgongo (Ngonya) and Bugamba (Misonga) (Fig. 1, Additional file 1: Table S1). In addition, one stream (Nyakageni River) within the largest urban area in the Kigoma Municipality (Kigoma Town) was included. Twelve sampling points were selected along each stream by pacing out the length of the river, with each point being located at least $200 \mathrm{~m}$ apart. The same sites were visited towards the end of the dry season (September) and in the wet season (October-April). Snails were systematically searched for at each point for a period of $15 \mathrm{~min}$ and sampled using a scoop ( 30 by $30 \mathrm{~cm}$ ) covered with a $2 \times 2 \mathrm{~mm}$ size mesh [24]. Individual snails were placed in separate plastic vials $(120 \mathrm{ml})$ and the containers wrapped with aluminum foil to keep light away and prevent the snails from shedding cercaria larvae before reaching the laboratory. Samples were analysed microscopically on the day of collection in a baboon research room at Gombe Stream Research Centre or at Mwamgongo Health Centre. Snails were identified morphologically as belonging to the genus Biomphalaria based on their blackish sinistral (left) coiled shell, following published identification guidelines [3]

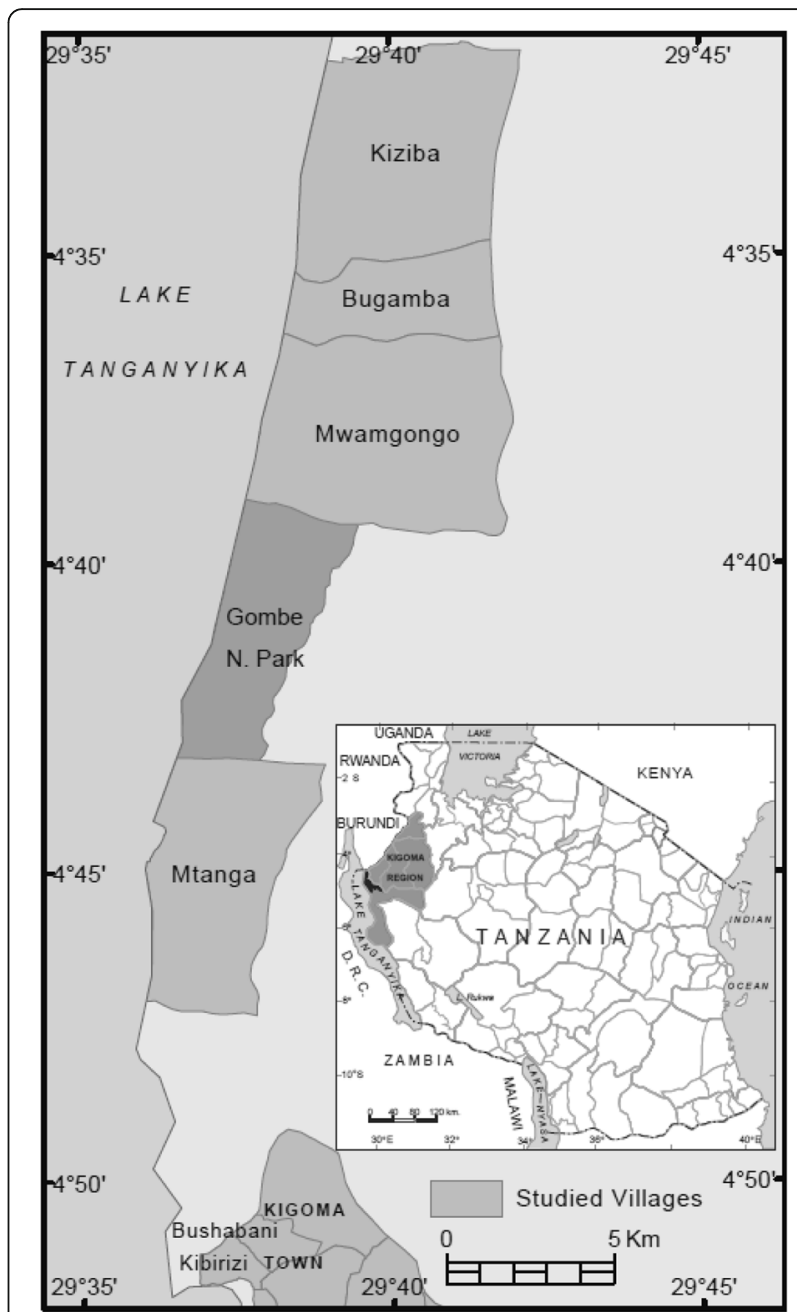

Fig. 1 The location of the study area (Gombe ecosystem) in the Kigoma region of western Tanzania (inset). The sampled streams from bottom to top are: Nyakageni in the Kibirizi area along Kigoma Bay in Kigoma town, Mtanga in Mtanga village, Kakombe and Mkenke in Gombe National Park; Ngonya in Mwamgongo, Misonga in Bugamba, and Bumba and an unnamed stream in Kiziba

and descriptions from previous reports on snail sightings in the region $[9,25]$.

\section{Shedding of parasite larvae (cercariae) from snails}

Snails were individually washed with distilled water and transferred into a well of 12- or 24-well plates containing filtered stream water. The plates were then exposed to artificial light $(60 \mathrm{~W})$ to enable the snails to shed cercariae [11]. After a period of 6 to $12 \mathrm{~h}$, each snail was observed under a dissecting microscope to determine if they were shedding schistosome larvae. Larval cercariae shed from the snails were morphologically identified to the genus level $[3,26]$. Each snail was then dissected and its tissue preserved in a 1:3 volume ratio of tissue to RNA-later solution at room temperature until required for DNA extraction [27]. 
DNA extraction and PCR amplification of snail tissues DNA extractions and PCR amplifications from snails were conducted at the University of Glasgow. Snail tissues were chopped into small pieces and DNA was extracted from up to $100 \mathrm{mg}$ using DNeasy ${ }^{\circ}$ Blood and Tissue Kits (Qiagen Inc., Manchester, UK). Polymerase chain reactions targeting the internal transcribed spacer region (ITS1) of the rDNA array were performed, using the primers ETTS2 (5'-TAA CAA GGT TTC CGT AGG TGA A-3') and ETTS17 (5'-CGA GCC GGA TGA TCC ACC GC-3'). Although these primers were designed to amplify multiple species of snails [20, 22], they also amplified trematode DNA [10], enabling a single PCR to confirm the identity of vectors (or hosts) and parasites. PCR was carried out in $20 \mu \mathrm{l}$ reactions containing $500 \mathrm{nM}$ of each primer, $1 \times$ Taq Reaction buffer, $2.5 \mathrm{mM}$ magnesium chloride, $0.05 \mathrm{U}$ Taq Polymerase (Invitrogen, Inc., Paisley, UK), $0.2 \mathrm{mM}$ dNTPs and $2 \mu \mathrm{l}$ DNA. Reaction volumes were brought to $20 \mu \mathrm{l}$ with water. The PCR profile consisted of an initial denaturing step at $95^{\circ} \mathrm{C}$ for $3 \mathrm{~min}$, followed by 34 cycles of denaturing at $95^{\circ} \mathrm{C}$ for $45 \mathrm{~s}$, annealing at $55^{\circ} \mathrm{C}$ for $60 \mathrm{~s}$, and extension at $72{ }^{\circ} \mathrm{C}$ for $60 \mathrm{~s}$. The cycle was completed with a final extension at $72{ }^{\circ} \mathrm{C}$ for $5 \mathrm{~min}$. For each set of reactions, a negative PCR control (using distilled water), and negative extraction controls (using just the extraction kit reagents) were run to check for contamination in the reagents used. A positive control using S. mansoni DNA extracted from faecal samples from known infected baboons in Gombe National Park was also run, to confirm the size band expected for the parasite.

To ensure that lack of amplification of parasites was not due to poor DNA quality, two approaches were used. First, only samples for which the snail band amplified cleanly were used for assessment of prevalence; in cases where this was not true, the PCR was repeated using new DNA extractions or by varying the concentration of DNA added to the PCR. Secondly, the DNA quality and quantity (in $\mathrm{ng} / \mu \mathrm{l}$ ) was assessed using a Nanodrop ${ }^{\circ}$ ND-1000 UV-Vis spectrophotometer and Nanodrop ND-1000 (V3.3.0) software. DNA quality was assessed based on the ratio between the absorbance values at $260 \mathrm{~nm}$ and $280 \mathrm{~nm}$ (260/280); for samples that deviated from a ratio of $1.8-2.0$, the DNA extractions were repeated on remaining tissue that had been preserved. Any sample sets showing evidence of contamination in the negative extraction controls were also repeated.

The presence of trematodes was assessed based on an amplification of a $500 \mathrm{bp}$ product (see [10]); species identification was confirmed by sequencing for a subset of samples. Any other size bands that amplified were also sequenced. A target of three infected and three uninfected snails from each population were selected for sequencing, to confirm species identity of both vectors and parasites. Prior to sequencing, amplified bands were excised from the gel and purified using Qiagen Gel extraction kits, using the manufacturer's protocol (Qiagen, Inc., Manchester, UK). Samples were sequenced at the GenePool (University of Edinburgh) using cycle sequencing with Big Dye and an ABI 3730 sequencer. Chromatographs were visualised and base-calling errors corrected using Sequencher version 4.5 (Gene Codes, Inc. Ann Arbor). Sequence identity of each amplified band was confirmed using mega BLAST (as implemented on the National Centre for Biotchnology Information, NCBI web portal) to identify the most similar sequences deposited to the GenBank nucleotide database.

\section{Results}

Snail distribution and shedding of parasite larvae (cercaria)

Snails were found in all streams except in Mtanga village, but their distribution was very patchy both in space and time (Additional file 1: Table S1). The highest numbers were found at Mwamgongo ( $n=95$ in September and $n=13$ in January), with seven of the 12 sampled points showing presence in September compared with only two in January. At the other sites, snails were predominantly found at one sampling time and at only one location along the streams. All collected snails were morphologically identified as B. pfeifferi.

Morphological examination of the cercaria larvae shed by snails revealed they were elongate and actively swimming and had a forked tail (furcocercous; tail stem longer than furcae) and a tapering head. Across sites, $12.3 \%$ of snails shed larvae, but there was extensive variation across streams (Table 1, Fig. 2). Strikingly, there was also a difference between sampling times at some sites: at Mwamgongo only 1/94 snails collected in September shed larvae, in contrast to $13 / 13$ sampled from the same stream positions in January. Based on microscopydetected cercarial shedding, no infected snails were found from Gombe or Bugamba and the levels of shedding were generally low in the other streams, including $8 / 30$ individuals from Kigoma and $7 / 29$ at unnamed stream in Kiziba village (Additional file 2: Table S2).

\section{Molecular identification of snails and schistosomes}

Out of the 235 sampled snails, PCR products were screened from 219 individuals (Table 1). From these, three size bands were consistently produced in PCR amplifications (Fig. 3): the 500 bp band predicted to correspond to $S$. mansoni, the $600 \mathrm{bp}$ band predicted to correspond to the snail host, and an unknown $1000 \mathrm{bp}$ band. If necessary, PCR for individual samples was repeated 2-6 times to ensure consistency of amplification 
Table 1 The numbers of snails sampled from the Gombe ecosystem and analysed for trematode infections by cercarial shedding and PCR. Infection prevalence is expressed as percent of snails screened; also indicated is the prevalence of another trematode (family Derogenidae), with a 1000 bp PCR product

\begin{tabular}{|c|c|c|c|c|c|}
\hline Village $^{a}$ & $\begin{array}{l}\text { No. of snails } \\
\text { sampled }\end{array}$ & $\begin{array}{l}\text { Prevalence S. mansoni } \\
\text { (shedding) }\end{array}$ & $\begin{array}{c}\text { No. of snails } \\
\text { screened }(P C R)^{c}\end{array}$ & $\begin{array}{c}\text { Prevalence } \\
(500 \text { bp band })^{c}\end{array}$ & $\begin{array}{c}\text { Prevalence } \\
\text { (1000 bp band) }\end{array}$ \\
\hline Bugamba & 23 & 0 & 23 & 34.8 & 26.1 \\
\hline Gombe & 46 & 0 & 32 & 0.08 & 0 \\
\hline Kigoma & 30 & 26.7 & 30 & 55.6 & 0 \\
\hline Kiziba & 28 & 24.1 & 28 & 54.2 & 0 \\
\hline Mwamgongo & 108 & 11.4 & 106 & 58.1 & 22.6 \\
\hline Total/average & 235 & 12.4 & 219 & 46.9 & 13.8 \\
\hline
\end{tabular}

${ }^{a}$ Mtanga village has been excluded from this table, as no snails were found

${ }^{b}$ All collected snails were tested for cercarial shedding and all shed cercaria confirmed to be S. mansoni based on morphology

c Species confirmation through sequencing was made for 8 individuals from Mwamgongo village, one individual each from Kiziba and Bugamba and two individuals from Gombe National Park. For Kigoma municipality, all three products sequenced were from an unknown trematode rather than S. mansoni Percentage prevalence based on PCR excludes individuals that did not show clear amplification of the snail band

of the snail band; 39 individuals had strong amplifications on the first attempt and so were not repeated. A total of 27 samples showed consistent lack of amplification of the snail band but three of these showed positive amplification of the $500 \mathrm{bp}$ band; the 24 samples that were negative for all bands were excluded from calculation of prevalence of the parasites. Clearly resolved sequences were obtained for: (i) the $600 \mathrm{bp}$ band from 10 uninfected and 10 infected snails; (ii) the $500 \mathrm{bp}$ band from 14 individuals; and (iii) the 1000 bp band from 4 individuals. Sequencing suggested that while species identification could usually be predicted based on the size fragment, there were some exceptions for both snails and parasites. Due to the extensive length variation, not all sequences could be aligned to one another but we have included an alignment to the closest matching sequences in GenBank, for each of the sequence types found (Additional file 3).

For the $600 \mathrm{bp}$ snail band, B. pfeifferi was confirmed using BLAST for 17 of the individuals sequenced. There was some variation among named $B$. pfeifferi sequences in GenBank, mostly in repeated regions and B. stanleyi

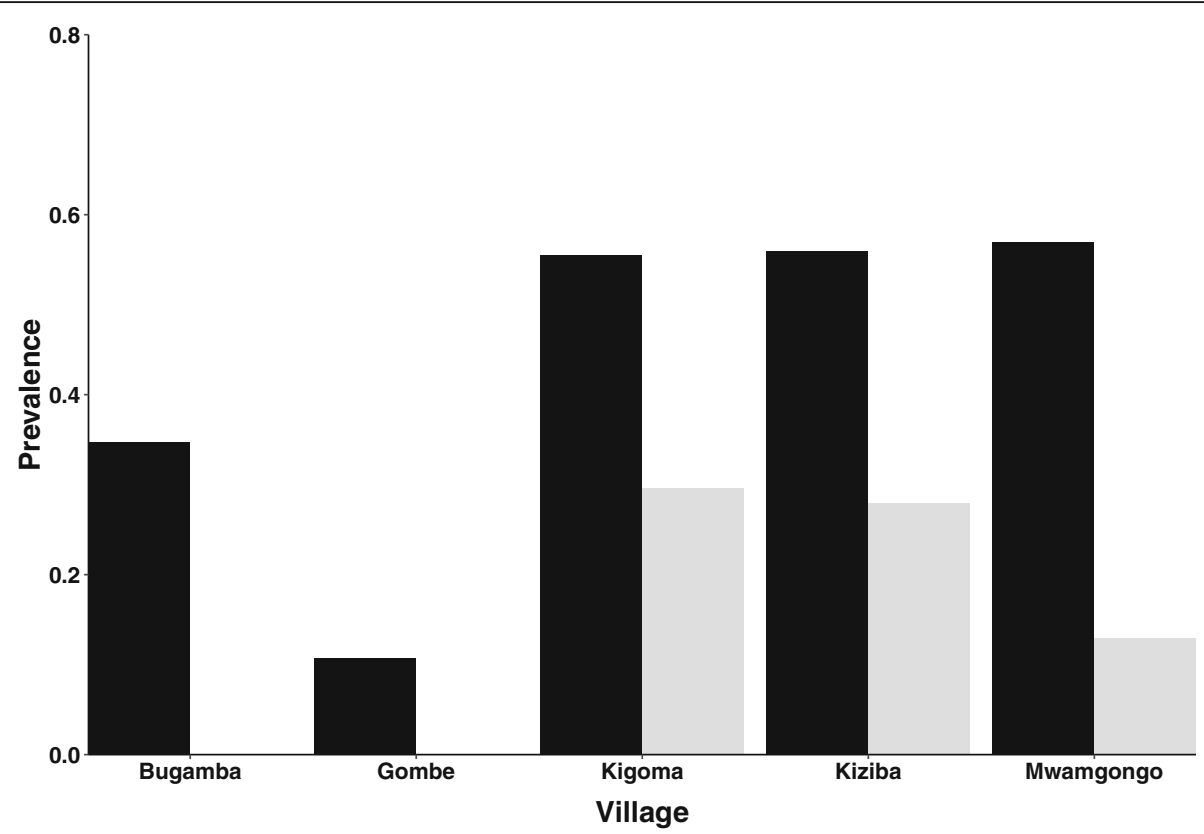

Fig. 2 Variation of S. mansoni infection in snails sampled from Gombe National Park and surrounding villages. Infection is based on percentage of snails sampled that shed larvae (light bars) or showed presence of a $500 \mathrm{bp}$ amplification product in PCR (dark bars). Note that S. mansoni was confirmed based on morphology for shed larvae and its presence was confirmed through PCR in all populations except Kigoma, where the 500 bp band was found to amplify a different species of trematode. Since not all products were sequenced, the presence of $S$. mansoni thus could be overestimated based only on PCR 


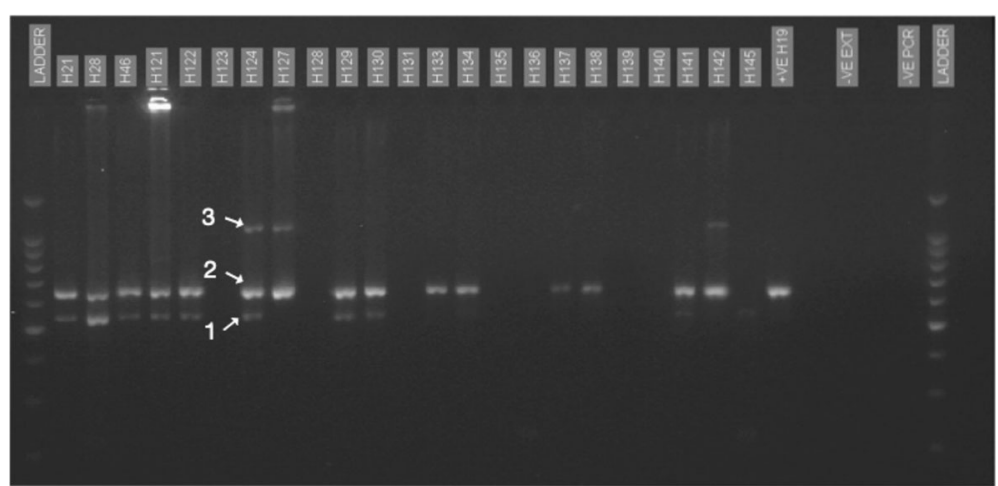

Fig. 3 Gel electrophoresis of PCR products of snail DNA with multiple bands. In Lane 8 (H124), the bands for the species detected are indicated by numbers: 1, size predicted for S. mansoni (500 bp); 2, size predicted for snails (600 bp); 3, amplification products of an unknown trematode (1000 bp). Also indicated are a positive control (+ve H19), a negative extraction control (-VE EXT) and a negative PCR control (-VE PCR)

was within the range of $B$. pfeifferi variation (Fig. 4a). Among the Gombe region samples, there were two different sequence variants, with a single nucleotide fixed difference between them. One type was found at most sites (type 1; GenBank: MG387092) (Fig. 4a, Additional file 2: Table S2 and Additional file 3), whereas the second was found only in the three samples sequenced from Bugamba (type 2; GenBank: MG387093). For the remaining three samples, a different sequence (labelled B. smithi-like; GenBank: MH387094) (Fig. 4a) was found for two individuals from Kigoma and one from Gombe (all collected during the wet season) that showed only 93\% similarity to the $B$. pfeifferi sequences (i.e. it differed at $45 /$
$643 \mathrm{bp})$. The closest matches in Genbank (99\% similarity in each case) were for B. smithi (AY030373; 576/578 bp), B. sudanica (AY030369; 574/577 bp), $B$. alexandrina (AY030372; 575/578 bp) and B. choanomphala (AY030370; 575/578 bp) [4]. However, these were all more similar to one another than to the $B$. pfeifferi sequences (Fig. 4a).

The $500 \mathrm{bp}$ trematode band was amplified in snails from all regions sampled and indicated a higher prevalence of infection than that based on cercarial shedding (Table 1, Fig. 3). After excluding samples that showed lack of amplification of the snail band in repeated amplifications, which might suggest poor quality DNA, $46.9 \%$ of samples were PCR positive; all except two snails that shed larvae were

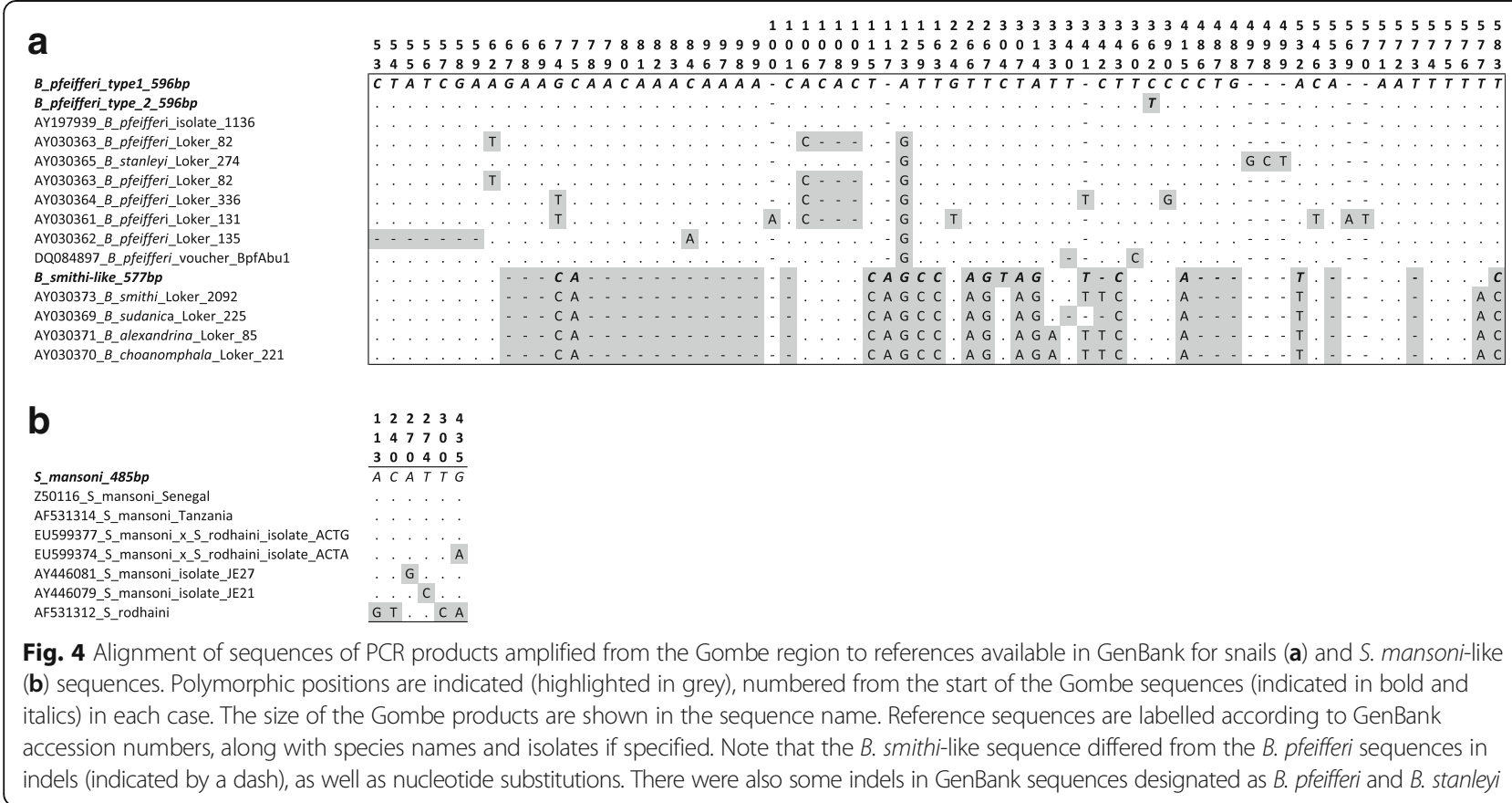


also PCR positive. The lowest prevalence of the $500 \mathrm{bp}$ band was found at Gombe (2/32 individuals), where no individuals shed larvae. The most striking difference between the two techniques were at: (i) Bugamba, where a relatively high percent of samples were PCR-positive for the target band (34.8\%) but no snails shed cercaria; and (ii) Mwamgongo, where all snails were both PCR- and cercarial shedding-positive in January but $52.4 \%$ were also PCR-positive in September, when only a single snail was found to be shedding larvae. Much higher prevalence based on PCR was also found at Kigoma (55.6\%) and Kiziba (54.2\%) than suggested by cercarial shedding (26.7\% and $24.1 \%$, respectively). The 500 bp band was amplified from both $B$. pfeifferi genotypes but not in snails identified as $B$. smithi, which also did not shed cercariae.

Sequences were obtained from 16 individual snails for the $500 \mathrm{bp}$ band. For 13 of these, identical sequences (GenBank: MG387089) were obtained that showed 100\% similarity to $S$. mansoni sequences available in GenBank over the $485 \mathrm{bp}$ of sequence obtained (Fig. 4b). These included African (Z50116 [28], AF531341 [29]) and Brazilian isolates (JG289742 [30]), as well as hybrids between S. mansoni and S. rodhaini (EU599377 [31]). The next most similar sequences were: (i) isolates of S. mansoni from Kenya (AY446081 [32]) and Brazil (AY446079 [32]), each showing $99 \%$ similarity ( $468 / 469 \mathrm{bp})$; and (ii) S. rodhaini (AF531312 [29]), which was also 99\% similar but showed more mismatches (465/469 bp) (Fig. 4b).

For three individuals sampled from Kigoma, although the band size was slightly larger but similar to that expected for S. mansoni (510 bp of sequence), an unknown trematode was amplified instead (GenBank: MG387090). The sequence was not alignable to the $S$. mansoni sequence and the next closest sequence was the trematode Macroderoides spiniferus (EU850403 [33]), which only showed $79 \%$ similarity over $78 \%$ of the sequence.

The 1000 bp band (Fig. 3) was present only at Bugamba (26.1\% of snails screened) and Mwangongo (22.6\%). Overall, 14/26 individuals that showed amplification of this band also tested PCR positive for the $S$. mansoni band, but none were observed to shed larvae. The band was sequenced for four snails from Mwamgongo; all were confirmed to be $100 \%$ identical to one another (GenBank: MG387091) but there were no similar sequences in GenBank. The closest matches were to trematode parasites with fish final hosts (family Derogenidae) from Japan (e.g. $72 \%$ identity over $89 \%$ of the sequence for Genarchopsis gigi; AB703652 [34]) but the low level of sequence overlap suggests low confidence.

\section{Discussion}

This study has confirmed the presence of schistosomeinfected snails in areas along the shores of Lake Tanganyika. Most of the snails were identified as B. pfeifferi, corroborating previous reports that the intermediate host for S. mansoni [35] occurs in the area [5, 6]. However, our study is the first to identify other species of snails and the different trematodes they carry using DNA sequencing. As consistently concluded by other studies [1], molecular analyses were more sensitive than cercarial shedding in detecting schistosome infections in snails but revealed some cautions about relying only on PCR-based diagnostics for parasite prevalence. Sequencing revealed that not all bands of the target size were $S$. mansoni and not all snails were B. pfeifferi. So, prevalence and infection risks could be overestimated if relying only on size fragment-based species identification.

\section{Molecular identification of snails}

Most sequenced snail samples were B. pfeifferi but some belonged to a sister clade resolved in recent phylogenetic analyses [4, 36]. All of the species in this clade are thought to be susceptible to $S$. mansoni and are able to transmit the parasite $[4,37]$. While the identity of the species was uncertain based on BLAST, any of the four candidates would represent a range extension to published distributions. Biomphalaria smithi has been reported in the nearby Democratic Republic of the Congo and further north on Lake Albert in Uganda $[36,38]$ while $B$. sudanica has only been described from the northern part of Tanzania, including Lake Victoria [6, 36]. Biomphalaria choanomphala has been thought to be endemic to Lake Victoria [6] while B. alexandrina is native to Egypt so its presence is less likely in Tanzania. A previous study compared relative susceptibility of widespread $B$. pfeifferi and $B$. sudanica with the more range-restricted $B$. stanleyi, B. smithi and B. choanomphala (which in Uganda are restricted to Lakes Albert, Edward and Victoria, respectively) when challenged with $S$. mansoni genotypes sampled from Lakes Albert and Victoria [39]. This revealed that the survival of infected snails increased when challenged with parasite strains sampled from a different geographical region, suggesting that geographical range expansions of snails could increase risk of schistosome transmission if snails are exposed to new parasite strains with which they have not previously been co-evolving.

The particular communities of parasites and vectors present could thus influence transmission dynamics. While some of the snails at Gombe were confirmed to be B. pfeifferi, B. smithi-like snails were also present. Since no snails in the park stream sampled shed schistosomes and only three were PCR positive, this could suggest that competition among potential vectors could affect transmission dynamics within a limited stream environment [37]. It is also informative that more than one genotype of $B$. pfeifferi was found among the snails sampled. For B. glabrata, which has its main distribution in South America, both resistant and susceptible genotypes 
of the snail can co-occur within a limited geographical region [4]. So, to increase understanding about the complex relationships among parasites, vectors and hosts [40], it could be important to identify not only the species of snails present but population genetic structure within species of snails that might impact relative susceptibility or vector competence [41].

\section{Distribution of trematodes based on cercarial shedding and molecular identification}

If the present conclusions about prevalence had been based on amplification of the $500 \mathrm{bp}$ band typical of $S$. mansoni, it would appear that the PCR technique was more sensitive than cercarial shedding, with schistosome infection detected in snails at an overall prevalence of $47 \%$ compared to only $12 \%$, respectively (Table 1, Fig. 2 ). This was particularly apparent at Bugamba, where no snails shed larvae but nearly a third of the snails tested showed amplification of the target band and at Mwangongo, where PCR and shedding showed dramatic differences. It is intriguing that both of these villages showed presence of the $1000 \mathrm{bp}$ band and that no samples showing presence of the $1000 \mathrm{bp}$ band shed $S$. mansoni larvae, even though a relatively large proportion also showed amplification of the $500 \mathrm{bp}$ band. The closest similarity of the $1000 \mathrm{bp}$ band was to trematodes with fishes as final hosts [34] but we could not distinguish whether this was a parasite present in the surrounding water or another trematode using snails as an intermediate host. However, this emphasises that relying only on shedding reduces the potential to consider the consequences of mixed infections.

While increased sensitivity and utility of PCR is consistent with many other studies [12, 16, 37, 39, 42-46], almost all have been based only on PCR-based identification, rather than sequencing. In our study, all three 500 bp amplicons sequenced from Kigoma showed amplification of a trematode other than $S$. mansoni (most similar to Macroderoides spiniferus, which has been reported to infect snails in Florida, with a fish final host [47]). Since the presence of B. pfeifferi was not confirmed through sequencing in this village, it is possible that the B. smithi-like snails found there transmit a different species of trematode. Competition among parasite genotypes or species within hosts is well known to affect fitness or virulence $[48,49]$ and so these findings could have important implications for transmission dynamics of schistosomes. Our results thus emphasise the importance of sequencing to confirm species identification of both intermediate hosts and parasites.

Our finding that the general primers used to simultaneously target both host and parasite also amplify other parasites present suggests that they provide a useful tool for assessing the role of intermediate hosts/vectors in transmitting multiple species of parasites. While other studies have recommended multiplex PCR [45] or qPCR [49], we have demonstrated the ease of using a single PCR reaction for identifying mixed infections. Multiplex PCR (either using specific primers in the same region to target different species or multiple gene regions to increase sensitivity) can be powerful but risk of differential amplification of products, hybridisation between products, and difficulties in resolving amplicons of similar size can create added complications in interpretation [50]. Our approach also has the advantage that amplification of the host DNA can act as an internal control for DNA quality, which is more difficult using multiplex approaches. qPCR can be extremely useful for targeting particular known species but is normally too specific to identify unknown parasites in mixed infections. Using any of these approaches, if it is important to know which species of parasites or vectors are present, sequencing is still critical to confirm identity, particularly when closely related species might have overlapping distributions. In our study, in terms of percent sequence similarity, $S$. rodhaini was the only species that fell within the range of $S$. mansoni isolates, although in terms of absolute differences there were more bp substitutions in the former. This suggests that use of the ITS region alone might not be sufficient to distinguish species within the mansoni group, but should be able to distinguish between other trematodes present. Sequencing of another variable region, such as the mitochondrial gene cytochrome $c$ oxidase subunit 1 could help to distinguish closely related species or populations of $S$. mansoni sampled from different geographical regions [51]. Resolving hybrids between trematode species [52] might also not be possible using our method because the ITS region can undergo concerted evolution [53]: our sequences were 100\% identical to hybrids between S. mansoni and S. rodhaini, which could suggest parental dominance in the rDNA repeats. We would thus recommend that the single PCR product approach provides a useful and cost-effective tool for resolving multiple infections but that more targeted approaches would need to be developed for finescale species identification within groups, based on extensive sampling across the range of each focal species and detailed analysis of cross-amplification [54].

\section{Distribution of infected snails in relation to S. mansoni prevalence in humans}

We found the highest abundance of snails at Mwamgongo, which was the only site where snails infected with $S$. mansoni were found both in the wet and dry seasons, with particularly high prevalence of the $500 \mathrm{bp}$ trematode band in the former (Fig. 3). This is also the village where the highest infection levels with $S$. mansoni were found in humans $(68 \%)$ in a parallel study, based on morphological 
identification of the parasites [10]. Schistosome-infected snails were also found in Bugamba, which also showed high prevalence of schistosomiasis in humans (61\%). In contrast, the lowest prevalence was found in Mtanga (19\%), where no B. pfeifferi-like snails were found. These observations are consistent with results from other studies, which have associated the focal distribution of schistosomiasis in humans to localized distribution and infection status of snails $[55,56]$. Even with the snapshot sampling that we used, the PCR-based screening of schistosome prevalence in snails could thus provide a useful screening method for predicting relative risk without more invasive human sampling.

\section{Conclusions}

Our study has demonstrated the power of combining PCR-based screening to diagnose parasite infections with sequencing to confirm the particular species of vectors and parasites interacting in a given region. The detection of multiple species of snails that have been implicated as intermediate hosts of S. mansoni in samples in a limited geographic region and the presence of multiple trematode species indicate the importance of not relying only on amplification of PCR products of a given size for surveillance informing intervention programmes for schistosomiasis and other infections. It also adds to the evidence that cercarial-shedding should not be relied on as a quantitative measure of relative prevalence, particularly when multiple species of parasites might be present in a region.

\section{Additional files}

Additional file 1: Table S1. Summary of sample sizes of snails collected for experimental shedding (number of snails collected) and PCR, along with the numbers of individuals per site within each sampled village that shed parasites or showed presence of the $500 \mathrm{bp}$ band expected for S. mansoni and the $1000 \mathrm{bp}$ band identified as another trematode. Also indicated is the number of PCR samples for which the snail band did not amplify (no. of snails negative for snail band); these were excluded from calculations of percentages for PCR-positive results. The sampling date, the season of sample collection, the stream name, and location of the villages are also indicated. (XLSX $15 \mathrm{~kb}$ )

Additional file 2: Table S2. Sampling locations and infection status of snails found in Gombe National Park and surrounding villages, showing the village/site and sampling points along the focal stream within each village, the individual code for the sample, the season sampled and whether schistosomes were detected through experimental shedding (microscopy) or presence of the $500 \mathrm{bp} \mathrm{PCR} \mathrm{band.} \mathrm{Presence} \mathrm{of} \mathrm{the}$ $1000 \mathrm{bp}$ band is also indicated, along with the species identification of snails and parasites based on sequencing. Mtanga stream in Mtanga villages where no snails were found has been excluded from this list. (XLSX $24 \mathrm{~kb}$ )

Additional file 3: Supplementary Sequence Information. This file provides the sequences (in FASTA format) that were obtained from sequencing each of the band sizes found using the primers ETTS2 and ETTS17, which target the ITS1 region of the ribosomal DNA array. For the $1000 \mathrm{bp}$ band, the sequences were not of sufficient quality to sequence through the entire fragment. For the other bands (approximately 600 bp for snails and 500 bp for trematodes), the size of the consensus sequence for the two primers is indicated, along with the sequence identity, as determined using BLAST. For the $1000 \mathrm{bp}$ product, only the sequence from the ETTS2 primer is provided. For B. pfeifferi, the type 1 and type 2 sequences only differ by a single nucleotide. For each sequence type, the closest matching sequences in GenBank are included. Alignment is only possible within and not between, sequence types, due to the large length variation. (TXT $20 \mathrm{~kb}$ )

\section{Abbreviations}

BLAST: Basic Local Alignment Search Tool; ITS: internal transcribed spacer; NCBI: National Centre for Biotechnology Information; NIMR: National Institute for Medical Research

\section{Acknowledgements}

Our appreciation goes to the Gombe Stream Research Centre and Gombe National Park authorities for logistical support during fieldwork. Special thanks go to the people in the studied villages for cooperation and to the Mwamgongo Health Centre in Kigoma District, Tanzania, for providing space for laboratory work. We also thank the Molecular Ecology Unit laboratory at the University of Glasgow, UK, for constructive advice during DNA analysis. This study was funded by a PhD studentship awarded to JSB by the Glasgow Centre for International Development. The comments from an anonymous reviewer substantially improved the manuscript.

\section{Funding}

Funding for this study was provided as a PhD studentship to JSB by the Glasgow Centre for International Development. The sponsor did not have any role or any influence whatsoever in the design of the study and collection, analysis, and interpretation of data and in writing the manuscript.

\section{Availability of data and materials}

The datasets supporting the conclusions of this article are included within the article and its additional files. Representative sequences are submitted in the GenBank database under the accession numbers MG387089-MG387094.

\section{Authors' contributions}

JSB conceived of the study, participated in its design, fieldwork and molecular laboratory work, as well as manuscript draft and writing. RG carried out most of the molecular laboratory work while BM participated in the study design, sequence alignment and analyses and revised the manuscript. GN participated in the design of the study and manuscript revision, while AA and EK supervised and contributed to the laboratory work. All authors read and approved the final manuscript.

\section{Authors' information}

JSB is a lecturer of Biology at Dar es Salaam University College of Education Tanzania. GN is a senior Lecturer of Parasitology at the University of Dar es Salaam, Tanzania. RG is a research technician at the University of Glasgow; this work was part of his honour's project research under the supervision of BKM and JSB. AA and EK are research technicians at Glasgow. BKM is a Professor of Evolutionary Genetics in the Institute of Biodiversity Animal Health and Comparative Medicine, University of Glasgow, UK.

\section{Ethics approval and consent to participate}

The Ethical Clearance (Ref. No. NIMR/HQ/R.8a/Vol.IX/892) for this study was issued by the Tanzania's National Institute for Medical Research (NIMR). The study did not report the use of any human subject.

\section{Consent for publication}

Not applicable.

\section{Competing interests}

The authors declare that they have no competing interests.

\section{Publisher's Note}

Springer Nature remains neutral with regard to jurisdictional claims in published maps and institutional affiliations. 


\section{Author details}

'Institute of Biodiversity, Animal Health and Comparative Medicine, College of Medical, Veterinary and Life Sciences, University of Glasgow, Glasgow, UK. ${ }^{2}$ Department of Biological Sciences, Dar es Salaam University College of Education, Dar es Salaam, Tanzania. ${ }^{3}$ Department of Zoology and Wildlife Conservation, University of Dar es Salaam, Dar es Salaam, Tanzania.

Received: 26 November 2016 Accepted: 6 November 2017

\section{Published online: 23 November 2017}

\section{References}

1. Stothard JR, Stanton MC, Bustinduy AL, Sousa-Figueiredo JC, Van Dam GJ, Betson M, et al. Diagnostics for schistosomiasis in Africa and Arabia: a review of present options in control and future needs for elimination. Parasitology. 2014;141(14):1947-61.

2. Utzinger J, Tanner M. Microhabitat preferences of Biomphalaria pfeifferi and Lymnaea natalensis in a natural and a man-made habitat in southeastern Tanzania. Mem Inst Oswaldo Cruz. 2000;95(3):287-94.

3. Brown DS. Freshwater snails of Africa and their medical importance. London: Taylor and Francis; 1994.

4. DeJong RJ, Morgan JAT, Paraense WL, Pointier JP, Amarista M, Ayeh-Kumi PFK, et al. Evolutionary relationships and biogeography of Biomphalaria (Gastropoda: Planorbidae) with implications regarding its role as host of the human bloodfluke, Schistosoma mansoni. Mol Biol Evol. 2001;18(12):2225-39.

5. Doumenge JP, Mott KE, Cheung C, Villeneve D, Chapuis O, Perrin MF, et al. Atlas of the global distribution of schistosomiasis. Talcence: Presses Universitaires de Bordeaux; 1987.

6. Magendantz M. The biology of Biomphalaria choanomphala and B. sudanica in relation to the their role in teh transmission of Schistosomosa mansoni in Lake Victoria, Tanzania. Bull World Health Organ. 1972;47(3):331-41.

7. Rugemalila JB. Schistosomiasis. In: Mwaluko GM, Kilama WL, Mandara MP, Murru M, McPherson CNL, editors. Health and diseases in Tanzania. New York: Harper Collins Academic Press; 1991. p. 145-58.

8. Nutter F. A comparison of gastrointestinal parasites in two communities of chimpanzees at Gombe national park. Tanzania: D.V.M. Dissertation, Tufts University School of Veterinary Medicine, North Grafton, Massachusetts; 1993.

9. Müller-Graf CDM, Collins DA, Packer C, Woolhouse MEJ. Schistosoma mansoni infection in a natural population of olive baboons (Papio Cynocephalus Anubis) in Gombe stream National Park, Tanzania. Parasitology. 1997;115:621-7.

10. Bakuza JS. Epidemiology of Schistosoma mansoni infection in sympatric humans and non-human primates in the Gombe ecosystem. Tanzania: PhD Thesis, University of Glasgow; 2012

11. Wolmarans $C T$, de Kock KN, Strauss HD, Bornman M. Daily emergence of Schistosoma mansoni and S. haematobium cercariae from naturally infected snails under field conditions. J Helminthol. 2002;76(3):273-7.

12. Hamburger J, Weil M, Ouma JH, Koech D, Sturrock RF. Identification of schistosome-infected snails by detecting schistosomal antigens and DNA sequences. Mem Inst Oswaldo Cruz. 1992;87:243-7.

13. Norton A, Rollinson D, Richards L, Webster J. Simultaneous infection of Schistosoma mansoni and S. rodhaini in Biomphalaria glabrata: impact on chronobiology and cercarial behaviour. Parasit Vectors. 2008;1:43.

14. Leger E, Webster JP. Hybridizations within the genus Schistosoma: implications for evolution, epidemiology and control. Parasitology. 2016:1-16.

15. Hamburger J, Weil M, Turetzky T, Ouma JH, Koech DK, Klumpp R, et al. Identification of snails infected with schistosomes by ELISA employing monoclonal antibodies - Schistosoma mansoni in laboratory snails (Biomphalaria glabrata) and in field snails (Biomphalaria pfeifferi) from Kenya. Am J Trop Med Hyg. 1989;40(6):613-9.

16. Hamburger J, Hoffman O, Kariuki HC, Muchiri EM, Ouma JH, Koech DK, et al. Large-scale, polymerase chain reaction-based surveillance of Schistosoma haematobium DNA in snails from transmission sites in coastal Kenya: a new tool for studying the dynamics of snail infection. Am J Trop Med Hyg. 2004; 71(6):765-73.

17. Hamburger J, Turetski T, Kapeller I, Deresiewicz R. Highly repeated short DNA sequences in the genome of Schistosoma mansoni recognized by a species-specific probe. Mol Biochem Parasit. 1991;44(1):73-80.

18. Caron Y, Rondelaud D, Losson B. The detection and quantification of a digenean infection in the snail host with special emphasis on Fasciola sp. Parasitol Res. 2008;103(4):735-44.
19. Born-Torrijos A, Poulin R, Raga JA, Holzer AS. Estimating trematode prevalence in snail hosts using a single-step duplex PCR: how badly does cercarial shedding underestimate infection rates? Parasit Vectors. 2014;7:243.

20. Plam M, Jørgensen A, Kristensen TK, Madsen H. Sympatric Biomphataria species (Gastropoda: Planorbidae) in Lake Albert, Uganda, show homoplasies in shell morphology. Afr Zool. 2008:43(1):34-44.

21. Kane RA, Rollinson D. Repetitive sequences in the ribosomal DNA internal transcribed spacer of Schistosoma haematobium, Schistosoma intercalatum and Schistosoma mattheei. Mol Biochem Parasit. 1994;63(1):153-6.

22. Stothard JR, Hughes $S$, Rollinson D. Variation within the internal transcribed spacer (ITS) of ribosomal DNA genes of intermediate snail hosts within the genus Bulinus (Gastropoda: Planorbidae). Acta Trop. 1996;61(1):19-29.

23. Hillis DM, Moritz C, Mable BK. Molecular Systematics. 2nd ed. Sunderland: Sinauer; 1996.

24. Madsen $\mathrm{H}$. Ecological field studies on schistosome intermediate hosts: relevance and methodological considerations. In: Madsen $\mathrm{H}$, Kristensen TK, Ndolovu P, editors. A status of research on medical malacology in relation to schistosomiasis in Africa. Proceedings from a Workshop held August $21^{\text {st }}$ to $25^{\text {th }}$ 1995. Harare, Zimbabwe: Danish Bilharziasis Laboratory and Blair Research Laboratory; 1996. pp. 67-87.

25. West K, Michel E, Todd JA, Brown D, Clabaugh J. The gastropods of Lake Tanganyika: diagnostic key and taxonomic classification with notes on the fauna. Internat Assoc Theoret Appl Limnol. 2003;2:1-132.

26. Jd M, MPNd S, Ohlweiler FP, Kawano T. Schistosoma mansoni and other larval trematodes in Biomphalaria tenagophila (Planorbidae) from Guarulhos, São Paulo state, Brazil. Rev Inst Med Trop Sao Paulo. 2009:51:77-82.

27. Webster BL. Isolation and preservation of schistosome eggs and larvae in RNAlater (R) facilitates genetic profiling of individuals. Parasit Vectors. 2009;2:50.

28. Kane RA, Ridgers IL, Johnston DA, Rollinson D. Repetitive sequences within the first internal transcribed spacer of ribosomal DNA in schistosomes contain a chi-like site. Mol Biochem Parasit. 1996;75(2):265-9.

29. Morgan JAT, DeJong RJ, Lwambo NJS, Mungai BN, Mkoji GM, Loker ES. First report of a natural hybrid between Schistosoma mansoni and S. rodhaini. J Parasitol. 2003;89(2):416-8.

30. Webster BL, Webster JP, Gouvras AN, Garba A, Lamine MS, Diaw OT, et al. DNA 'barcoding' of Schistosoma mansoni across sub-Saharan Africa supports substantial within locality diversity and geographical separation of genotypes. Acta Trop. 2013;128(2):250-60.

31. Steinauer ML, Agola LE, Mwangi IN, Mkoji GM, Loker ES. Molecular epidemiology of Schistosoma mansoni: a robust, high-throughput method to assess multiple microsatellite markers from individual miracidia. Infect Genet Evol. 2008;8(1):68-73.

32. Morgan JAT, Dejong RJ, Adeoye GO, Ansa EDO, Barbosa CS, Bremond P et al. Origin and diversification of the human parasite Schistosoma mansoni. Mol Ecol. 2005;14(12):3889-902.

33. Tkach W, Strand EJ, Froese L. Macroderoides texanus n. sp (Digenea: Macroderoididae) from alligator gar, Atractosteus spatula in Texas. Parasitol Res. 2008;104(1):27-33.

34. Urabe M, Nishimura T, Shimazu T. Taxonomic revision of three species of the genus Genarchopsis (Digenea: Hemiuroidea: Derogenidae) in Japan by molecular phylogenetic analyses. Parasitol Int. 2012;61(4):554-60.

35. Southgate RV, Rollinson D. Natural history of transmission and schistosome interactions. In: Rollinson D, Simpson AJD, editors. The biology of schistosomes: from genes to latrines. London: Academic Press; 1987. p. 116-46.

36. Jørgensen A, Kristensen TK, Stothard JR. Phylogeny and biogeography of African Biomphalaria (Gastropoda: Planorbidae), with emphasis on endemic species of the great east African lakes. Zool J Linnean Soc. 2007;151(2):337-49.

37. Rowel C, Fred B, Betson M, Sousa-Figueiredo JC, Kabatereine NB, Stothard $J R$. Environmental epidemiology of intestinal schistosomiasis in Uganda: population dynamics of Biomphalaria (Gastropoda: Planorbidae) in Lake Albert and Lake Victoria with observations on natural infections with digenetic trematodes. Biomed Res Int. 2015;2015:11.

38. Biomphalaria smithi [www.iucnredlit.org/details/184653/0]. Accessed 6 Jan 2016.

39. Adriko M, Standley CJ, Tinkitina B, Mwesigwa G, Kristensen TK, Stothard JR, Kabatereine NB. Compatibility of Ugandan Schistosoma mansoni isolates with Biomphalaria snail species from Lake Albert and Lake Victoria. Acta Trop. 2013;128(2):303-8.

40. Rollinson D, Knopp S, Levitz S, Stothard JR, Tchuente LAT, Garba A, et al. Time to set the agenda for schistosomiasis elimination. Acta Trop. 2013; 128(2):423-40. 
41. Standley CJ, Goodacre SL, Wade CM, Stothard JR. The population genetic structure of Biomphalaria choanomphala in Lake Victoria, East Africa: implications for schistosomiasis transmission. Parasit Vectors. 2014;7:524.

42. Hung NM, Dung TD, Anh NTL, Van PT, Thanh BN, Ha NV, et al. Current status of fish-borne zoonotic trematode infections in Gia Vien district, Ninh Binh province, Vietnam. Parasit Vectors. 2015;8:21.

43. Abbasi I, King CH, Muchiri EM, Hamburger J. Detection of Schistosoma mansoni and Schistosoma haematobium DNA by loop-mediated isothermal amplification: identification of infected snails from early prepatency. Am J Trop Med Hyg. 2010;83(2):427-32.

44. Hamburger J, He- N, Xin XY, Ramzy RM, Jourdane J, Ruppel A. A polymerase chain reaction assay for detecting snails infected with bilharzia parasites (Schistosoma mansoni) from very early prepatency. Am J Trop Med Hyg. 1998;59(6):872-6.

45. Jannotti-Passos LK, Magalhaes KG, Carvalho OS, Vidigal THDA. Multiplex PCR for both identification of Brazilian Biomphalaria species (Gastropoda: Planorbidae) and diagnosis of infection by Schistosoma mansoni (Trematoda: Schistosomatidae). J Parasitol. 2006;92(2):401-3.

46. Melo FL, Gomes ALD, Barbosa CS, Werkhauser RP, Abath FGC. Development of molecular approaches for the identification of transmission sites of schistosomiasis. Trans R Soc Trop Med Hyg. 2006;100(11):1049-55.

47. Leigh WH. The life history of Macroderoides spiniferus Pearse, 1924, a trematode of the Florida spotted gar, Lepisosteus platyrhincus. J Parasitol. 1958:44(4):379-87.

48. Gower CM, Webster JP. Intraspecific competition and the evolution of virulence in a parasitic trematode. Evolution. 2005:59(3):544-53.

49. Thiele EA, Minchella DJ. Molecular assessment of trematode co-infection and intraspecific competition in molluscan intermediate hosts. Mol Biochem Parasit. 2013;187(1):52-9.

50. Jørgensen MH, Lagesen K, Mable BK, Brysting AK. Using highthroughput sequencing to investigate the evolution of selfincompatibility genes in the Brassicaceae: strategies and challenges. Plant Ecology \& Diversity. 2012;5(4):473-84.

51. Stothard JR, Webster BL, Weber T, Nyakaana S, Webster JP, Kazibwe F, et al. Molecular epidemiology of Schistosoma mansoni in Uganda: DNA barcoding reveals substantial genetic diversity within Lake Albert and Lake Victoria populations. Parasitology. 2009;136(13):1813-24.

52. Steinauer ML, Blouin MS, Criscione CD. Applying evolutionary genetics to schistosome epidemiology. Infect Genet Evol. 2010;10(4):433-43.

53. Hillis DM, Davis SK. Ribosomal DNA: Intraspecific polymorphism, concerted evolution, and phylogeny reconstruction. Syst Zool. 1988;37:63-6.

54. He P, Song L-g, Xie H, Liang J-y, Yuan D-y, Wu Z-d, Lv Z-y. Nucleic acid detection in the diagnosis and prevention of schistosomiasis. Infect Dis Poverty. 2016;5:25.

55. Goll PH, Wilkins HA. Field studies on Bulinus senegalensis Muller and the transmission of Schistosoma haematobium infection in a Gambian community. Tropenmed Parasitol. 1984;35(1):29-36.

56. Scott D, Senker K, England EC. Epidemiology of human Schistosoma haematobium infection around Volta Lake, Ghana, 1973-75. Bull World Health Organ. 1982;60(1):89-100.

\section{Submit your next manuscript to BioMed Central and we will help you at every step:}

- We accept pre-submission inquiries

- Our selector tool helps you to find the most relevant journal

- We provide round the clock customer support

- Convenient online submission

- Thorough peer review

- Inclusion in PubMed and all major indexing services

- Maximum visibility for your research

Submit your manuscript at www.biomedcentral.com/submit 